\title{
Skin reactivity and fibronectin-binding property of TB66 (66-kDa protein of Mycobacterium tuberculosis)
}

\author{
RAJASHRI G. DESHPANDE, MAHFUZ B. KHAN, DEEPASHREE A. BHAT and R. G. NAVALKAR* \\ Department of Microbiology and Immunology, Morehouse School of Medicine, 720 Westview Drive SW, Atlanta, \\ Georgia 30310, USA
}

\begin{abstract}
Summary. A 66-kDa protein (TB66) was purified from culture filtrate (CF) and cell sonicate (CS) of Mycobacterium tuberculosis $\mathrm{H}_{37} \mathrm{Rv}$ by immobilised metal affinity chromatography (IMAC) on a Ni-nitrilotriacetic acid (NTA) column. TB66 was found to be a fibronectinbinding protein as determined by ELISA and could be purified by affinity chromatography with fibronectin-Sepharose. A similar 66-kDa protein could be isolated also from M. bovis, $M$. bovis BCG, M. africanum and $M$. tuberculosis $\mathrm{H}_{37}$ Ra by IMAC, but not from any other mycobacteria. The $\mathrm{NH}_{2}$-terminal amino-acid sequence of $\mathrm{TB} 66$ from $\mathrm{H}_{37} \mathrm{Rv}$ and $M$. bovis was identical and showed $85 \%$ homology with the $\mathrm{N}$-terminal sequence of bovine serum albumin (BSA). A monoclonal antibody (MAb) OD4AG3 recognised a heat-stable and trypsin-sensitive epitope near the C-terminal end of TB66. This MAb also recognised the 66-kDa protein isolated from the other members of the M. tuberculosis complex. In tests of immunogenicity, TB66 elicited a delayed type hypersensitivity reaction in guinea-pigs immunised with either TB66 or with M. tuberculosis H37Rv. TB66 also elicited an antibody response in immunised guinea-pigs and stimulated murine macrophages to produce tumour necrosis factor.
\end{abstract}

\section{Introduction}

Mycobacterial diseases continue to be important causes of human morbidity and mortality. It is estimated that tuberculosis is responsible for as many as $26 \%$ of all avoidable adult deaths worldwide. ${ }^{1}$ The tubercle bacillus contains several immunologically active components, most of which are widely shared among other mycobacterial species. ${ }^{2}$ The development of nðvel vaccines and diagnostic tests for tuberculosis requires purified and well characterised antigens that are immunologically active and species-specific. However, the complex nature and chemical diversity which characterise the antigens of pathogenic mycobacteria have limited the preparation of pure, specific and standardisable protein antigens by the classical methods of purification from culture filtrates and cell extracts. ${ }^{3,4}$

Secreted antigens of Mycobacterium tuberculosis may be of particular significance in the development of protective immunity. Some secreted antigens have been shown to bind fibronectin $(\mathrm{FN}){ }^{5}$ FN-binding antigens are prominent components of short-term

Received 17 March 1994; accepted 8 June 1994

* Correspondence should be sent to Professor R. G. Navalkar. culture filtrates (CF) of $M$. tuberculosis. ${ }^{6} \mathrm{FN}$, a large glycoprotein commonly found in plasma and extracellular matrices, has many biological activities. It binds to various macromolecules and participates in cell-surface interactions between eukaryotic cells and micro-organisms. ${ }^{7}$ It has been demonstrated that mycobacteria bind to FN and that BCG CF inhibited attachment of organisms to FN-coated surfaces. ${ }^{8}$ The $30 / 31-\mathrm{kDa}$ proteins and $57-60-\mathrm{kDa}$ proteins of $M$. tuberculosis have been shown to be FN-binding proteins. ${ }^{6}$ Mycobacteria and mycobacterial proteins are also known to be potent inducers of monocyte-derived tumour necrosis factor (TNF). ${ }^{9,} 10$

We have identified a novel seroreactive $66-\mathrm{kDa}$ protein (TB66) in cell sonicates (CS) and in short-term CF of $M$. tuberculosis. ${ }^{11}$ The present study was aimed at further characterising this protein to determine its role in vivo.

\section{Materials and methods}

\section{Preparation of CS and CF}

M. tuberculosis $\mathrm{H}_{37} \mathrm{Rv}, M$. avium serotypes 4 and 8, $M$. kansasii and $M$. fortuitum (obtained from Dr T. Daniel, Case Western Reserve University, Cleveland, 
$\mathrm{OH}, \mathrm{USA}), M$. tuberculosis $\mathrm{H}_{37} \mathrm{Ra}$ and $M$. bovis $\mathrm{BCG}$ (obtained from Dr J. Crawford, Centers for Disease Control and Prevention, Atlanta, GA, USA), $M$. bovis ATCC 35740 and $M$. africanum ATCC 25420 were grown in Middlebrook 7H9 Broth (Difco Laboratories) without $\mathrm{ADC}$ enrichment at $37^{\circ} \mathrm{C}$. Threeweek-old cultures were harvested aseptically by centrifugation. The $\mathrm{CF}$ was filter-sterilised by passing through a $0.45-\mu \mathrm{m}$ filter and refrigerated before use. The cells were washed and suspended in saline and sonicated in ice in four continuous cycles of 3 min each with a W-375 sonicator (Heat Systems-Ultrasonics, Plainview, NY, USA) with a $100-\mathrm{W}$ energy output. The supernate obtained after centrifugation of the sonicated cells was used as the CS. Sonicates of $M$. intracellulare, $M$. phlei, $M$. chelonae, $M$. xenopi, $M$. szulgai, M. vaccae, M. marinum, M. smegmatis and $M$. scrofulaceum were kindly provided by $\mathrm{Dr}$ S. Chaparas, Bureau of Biologics, FDA, NIH, Rockville, MD, USA. The sonicate of irradiated purified armadilloderived $M$. leprae cells (provided by Dr P. J. Brennan, Colorado State University, CO, USA) was prepared as described above. Protein was determined by the BioRad protein assay system (BioRad Laboratories, Richmond, CA, USA).

\section{Monoclonal antibodies}

Murine monoclonal antibodies (MAbs) were raised in this laboratory against the soluble sonicate of $M$. avium complex (MAC101). During the screening of the culture supernates obtained from the clones, one clone (OD4AG3) was found to produce a MAb that cross-reacted with $\mathrm{H}_{37} \mathrm{Rv}$ sonicate in ELISA. On Western blotting, this MAb was found to react with an M. tuberculosis protein with an $\mathrm{M}_{\mathrm{r}}$ of $c .66 \mathrm{kDa}$.

\section{Immobilised metal affinity chromatography (IMAC)}

Proteins were purified with a nickel nitrilotriacetic acid (Ni-NTA) resin ${ }^{12}$ under non-denaturing conditions as described previously. ${ }^{11}$ Briefly, columns containing $c .1 \mathrm{ml}$ of Ni-NTA resin (Qiagen, Chatsworth, CA, USA) were equilibrated with buffer A $(0.5 \mathrm{M}$ sodium phosphate buffer containing $0.5 \mathrm{M} \mathrm{NaCl}$, $\mathrm{pH}$ 8.0). The CS and CF (in buffer A) were then loaded on to the column. The column was washed with buffer A until absorbance at $280 \mathrm{~nm}\left(\mathrm{~A}_{280}\right)$ was 0 , and bound proteins were eluted with buffer $\mathrm{B}$ ( $10 \mathrm{mM}$ potassium phosphate buffer containing $0.75 \mathrm{M} \mathrm{NH}_{4} \mathrm{Cl}, \mathrm{pH} 6 \cdot 6$ ). Samples ( $2 \mathrm{ml}$ ) were collected and those showing $\mathbf{A}_{280}$ $>0$ were analysed by SDS-PAGE with acrylamide $12 \%$ gels (Mini-Protean II ready gels, BioRad) followed by Coomassie Brilliant Blue R-250 (CBB) staining. Fractions containing the $66-\mathrm{kDa}$ protein (typically the first two to three samples) were pooled, dialysed and used for further studies.

\section{Fibronectin-Sepharose chromatography}

The $\mathrm{CF}$ of strain $\mathrm{H}_{37} \mathrm{Rv}$ was subjected to FNSepharose chromatography. Plasma FN (Sigma) was bound to gelatin-Sepharose (Sigma) by the method of Vuento. ${ }^{13} \mathrm{CF}$ from strain $\mathrm{H}_{37} \mathrm{Rv}$ was then applied to

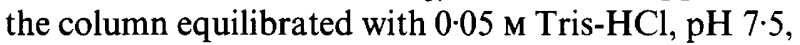
and material bound to $\mathrm{FN}$ was eluted with $1 \mathrm{M} \mathrm{NaCl}$ or with $20 \mathrm{~mm}$ EDTA in Tris buffer; 2-ml fractions were collected and assayed for the presence of protein by SDS-PAGE.

\section{Amino terminal sequencing}

The 66-kDa protein obtained from $\mathrm{CF}$ of strain $\mathrm{H}_{37} \mathrm{Rv}$ and $M$. bovis was transferred electrophoretically from an SDS-PAGE gel to polyvinylidine difluoride membranes $(0.2 \mu \mathrm{m}$, BioRad $)$ with the Transblot apparatus at a constant current of $270 \mathrm{~mA}$ for $90 \mathrm{~min}$. The transfers were stained for $1 \mathrm{~min}$ in Coomassie Blue, destained briefly in methanol $40 \%$ and acetic acid $10 \%$ in water, washed in distilled water, and air-dried. Protein was cut from the membrane and amino terminal sequencing was performed by Dr J. Pohl, Emory University, Atlanta, GA, USA. Searches of the Gen Bank (release 72.0) and SWISSPROT (release 22.0) databases were conducted by FASTA software to determine sequence homology.

\section{Western blotting}

The 66-kDa proteins obtained by IMAC were subjected to SDS-PAGE $12 \%$ and transferred electrophoretically from the gel to nitrocellulose membranes $(0.2 \mu \mathrm{m}$ pore size, BioRad) by the method of Towbin $e t$ al. ${ }^{14}$ with a Trans-blot apparatus (BioRad) and LKB 2002 Power supply. MAb OD4AG3 was used as the primary antibody. Peroxidase conjugated rabbit antimouse polyvalent immunoglobulin (BioRad) diluted 1 in 1000 was used as the secondary antibody. The reaction was visualised with 4-chloro-1-naphthol and $\mathrm{H}_{2} \mathrm{O}_{2}$ as the substrate, and was stopped by washing the membrane in distilled water.

\section{Dot immunobinding assay}

The assay was performed as described previously. ${ }^{15}$ Briefly, TB66 obtained from strain $\mathrm{H}_{37} \mathrm{Rv} \mathrm{CF}$ and CS was spotted on nitrocellulose and air-dried. The subsequent immunoassay was performed as described above. MAb OD4AG3 was used as the primary antibody and the effect of trypsin and carboxypeptidase on the reactivity of TB66 was determined by incubating the protein with each enzyme before assessment of its immunoreactivity.

\section{Detection of FN-binding property of TB66}

The ability of TB66 to bind FN was determined in two ways by ELISA. (1) TB66 ( $1 \mu \mathrm{g} /$ well) was added to wells of a microtitration plate (Falcon, BectonDickinson Labware, NJ, USA) coated with FN 
( $1 \mu \mathrm{g} /$ well). Bound protein was detected by MAb OD4AG3. (2) FN was added to wells coated with TB66 $(1 \mu \mathrm{g} /$ well) and bound FN was detected with affinity purified rabbit anti-FN polyclonal antibody (Sigma). Controls included TB66 added to bovine serum albumin (BSA)-coated wells and FN-coated wells without TB66. The reaction was visualised with the appropriate peroxidase conjugated secondary antibody, and $o$-phenylene diamine dihydrochloride and $\mathrm{H}_{2} \mathrm{O}_{2}$ as the substrate. The extinction was measured in a Titertek Multiskan reader at $492 \mathrm{~nm}$.

\section{DTH reaction}

Three groups, each consisting of three male Hartley strain guinea-pigs weighing $400 \mathrm{~g}$ each, were used for the study. Each animal from groups I and II was given two subcutaneous injections, 3 weeks apart, of $\mathrm{H}_{37} \mathrm{Rv}$ sonicate containing $1 \mathrm{mg}$ of protein and $200 \mu \mathrm{g}$ TB66 (from $\mathrm{H}_{37} \mathrm{Rv} \mathrm{CF}$ ), respectively, in incomplete Freund's adjuvant (IFA). Animals in group III formed the control group and were given IFA only. Three weeks after the second injection, all the animals were tested with $0 \cdot 1-\mathrm{ml}$ intradermal injections of $\mathrm{H}_{37} \mathrm{Rv}$ sonicate $(5 \mu \mathrm{g})$, TB66 of $\mathrm{H}_{37} \mathrm{Rv}$ (1 and $5 \mu \mathrm{g}$ ) and PPD. PPD (5 tuberculin units corresponding to protein $0.4 \mu \mathrm{g} / 0 \cdot 1$ $\mathrm{ml}$ ) was kindly provided by Dr J. Crawford (CDC, Atlanta, USA). The reactions (diameter of erythema and induration) were read at 18, 24, 48 and $72 \mathrm{~h}$. The animals were bled by cardiac puncture after $72 \mathrm{~h}$ and the serum from each animal was tested by ELISA for the presence of antibodies to TB66. Subsequently, sera from each group were pooled and the antibody titre was determined. The titre was defined as the last serum dilution that gave a positive reaction with TB66.

\section{TNF assay}

Supernates containing TNF activity were generated by adding TB66 to 16-mm diameter tissue-culture wells (Falcon) containing $10^{6}$ mouse macrophages of J774 (American Type Culture Collection [ATCC], Rockville, MD, USA) in $1 \mathrm{ml}$ of RPMI 1640 medium supplemented with $2 \mathrm{mM}$ L-glutamine, penicillin 100 units $/ \mathrm{ml}$ and streptomycin $100 \mu \mathrm{g} / \mathrm{ml}$. The macrophages were incubated with TB66 $(5 \mu \mathrm{g})$ at $37^{\circ} \mathrm{C}$ in air with $\mathrm{CO}_{2} 5 \%$ and harvested at 22-24 h. Control wells contained macrophages incubated without TB66. In some wells, TNF activity was generated by stimulation of macrophages with bacterial LPS (10 $\mu \mathrm{g}$, Sigma). TB66 was also pre-incubated for $1 \mathrm{~h}$ at $37^{\circ} \mathrm{C}$ with MAb OD4AG3 before addition to macrophages, to determine whether this MAb neutralised TB66 and prevented it from stimulating the macrophages. As a control, MAb OD4AF1 (which does not recognise TB66) was also pre-incubated with TB66 and then added to the macrophages. The supernates were collected after sedimentation of the cells and were stored at $-20^{\circ} \mathrm{C}$ until the time of assay. TNF activity was assessed by cytotoxicity for murine L-929 fib- roblasts (ATCC) by the method described by Flick and Gifford ${ }^{16}$ with some modifications. Supernates from experimental and control wells were added to confluent monolayers of L-929 fibroblasts obtained by incubation of cells at a density of $2.5 \times 10^{4}$ cells/ $0.1 \mathrm{ml} /$ well (flat-bottomed tissue culture treated plates; Corning, NY, USA) in fetal bovine serum $20 \%$ and modified Eagle's medium for $24-48 \mathrm{~h}$ at $37^{\circ} \mathrm{C}$. Actinomycin $\mathrm{D}(1 \mu \mathrm{g} / \mathrm{ml})$ was added to each well and the cells were incubated for $20 \mathrm{~h}$ at $37^{\circ} \mathrm{C}$. Cell lysis was determined by staining viable cells with $50 \mu$ of neutral red dye $(0.1 \% \mathrm{w} / \mathrm{v})$ in phosphate-buffered saline (PBS) for $1 \mathrm{~h}$ at $37^{\circ} \mathrm{C}$. The stained cells were washed with PBS and lysed with ethanol $50 \%-0 \cdot 1 \mathrm{M}$ monobasic sodium phosphate. Absorbance of neutral red was measured at $570 \mathrm{~nm}$ with a Titertek Multiskan reader. Measurements were the mean of eight replicates. The cytotoxicity of TB66 towards the fibroblasts, if any, was determined by incubating the protein with the fibroblasts and performing the assay as above. Cytotoxicity was defined as a reduction in the neutral red uptake by the fibroblasts which was observed as a decrease in absorbance of neutral red.

\section{Results}

\section{Purification of TB66}

$N i$-NTA chromatography. IMAC of CS and CF of strains $\mathrm{H}_{37} \mathrm{Rv}, \mathrm{H}_{37} \mathrm{Ra}, M$. bovis, $\mathrm{BCG}$ and $M$. africanum yielded fractions that contained predominantly a protein with an $M_{r}$ of $66 \mathrm{kDa}$. Fig. $1 \mathrm{a}-\mathrm{e}$ shows the Ni-NTA eluates obtained from the CF of these organisms. No binding to Ni-NTA was observed with any other mycobacterial CS or CF tested. Sterile 7H9 broth showed no binding to Ni-NTA.

FN-Sepharose chromatography. The experimental conditions used allowed the binding of FN to gelatinSepharose for subsequent use in the isolation of FNbinding proteins. $\mathrm{CF}$ of strain $\mathrm{H}_{37} \mathrm{Rv}$ bound to FNSepharose and the bound material could be eluted with $\mathrm{NaCl}$ as well as EDTA. The eluates showed the presence of a 66-kDa protein by SDS-PAGE (fig. $1 \mathrm{f}$ and g). CF did not bind to gelatin-Sepharose which was not coupled to $\mathrm{FN}$. Also, $\mathrm{NaCl}$ or EDTA did not wash away the FN that was bound to the gelatinSepharose column.

\section{Characterisation of TB66}

The N-terminal amino-acid sequence of TB66 (from CS and $\mathrm{CF}$ ) from strain $\mathrm{H}_{37} \mathrm{Rv}$ and from $M$. bovis was found to be identical. The sequence was determined to be ASP-LYS/THR-HIS-LYS-SER-GLU-ILE-ALAHIS-ARG-PHE-LYS-ASP-LEU-GLY-GLU-XXXPRO-PHE-LYS and it was found to have $85 \%$ identity with the $\mathrm{N}$-terminal sequence of BSA. Binding of FN to TB66 (coated to the wells of a polystyrene plate) could be detected in ELISA with anti-FN antibody 


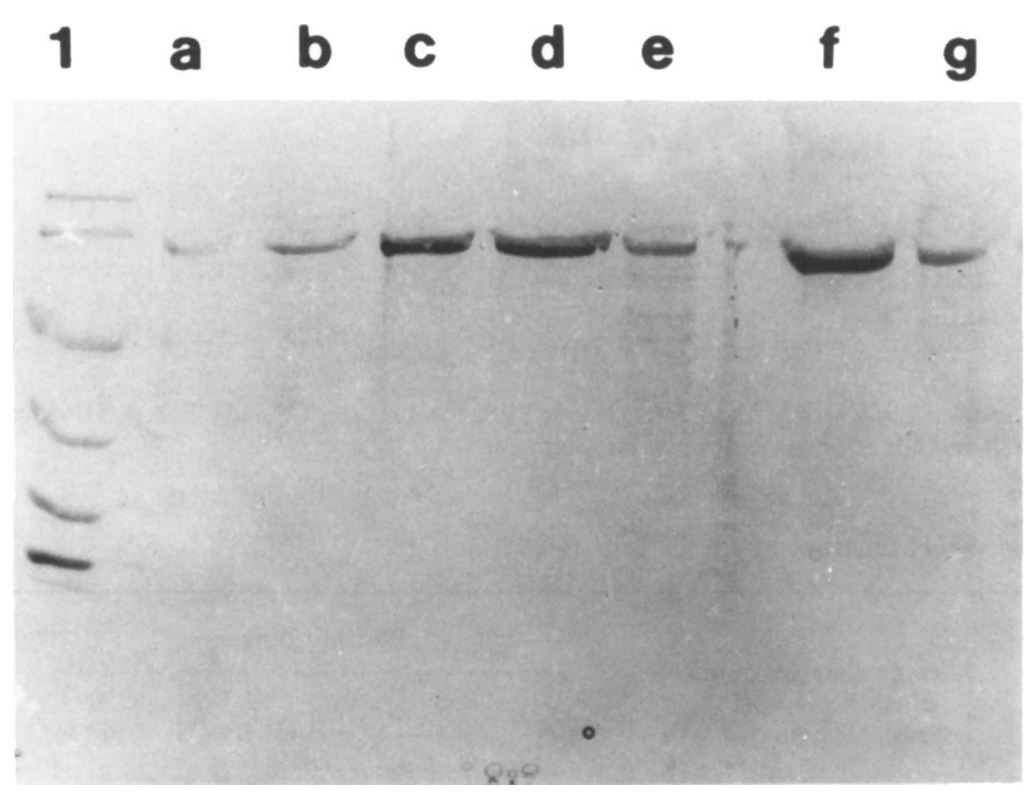

Fig. 1. SDS-PAGE (12\%) of fractions obtained by IMAC of: a, M. bovis BCG; b, $\mathrm{H}_{37} \mathrm{Ra} ; \mathbf{c}, M$. bovis; d, $\mathrm{H}_{37} \mathrm{Rv} ;$ M. africanum; and those obtained by (f) $\mathrm{NaCl}$ or (g) EDTA elution of $\mathrm{FN}$-Sepharose bound material of $\mathrm{H}_{32} \mathrm{Rv}$ CF. Lane 1, mol. wt (kDa) markers (top to bottom: phosphorylase b, 97.4; bovine serum albumin, 66.2; ovalbumin, 43 ; carbonic anhydrase, 31 ; soybean trypsin inhibitor, 21.5 ; lysozyme, 14.4).

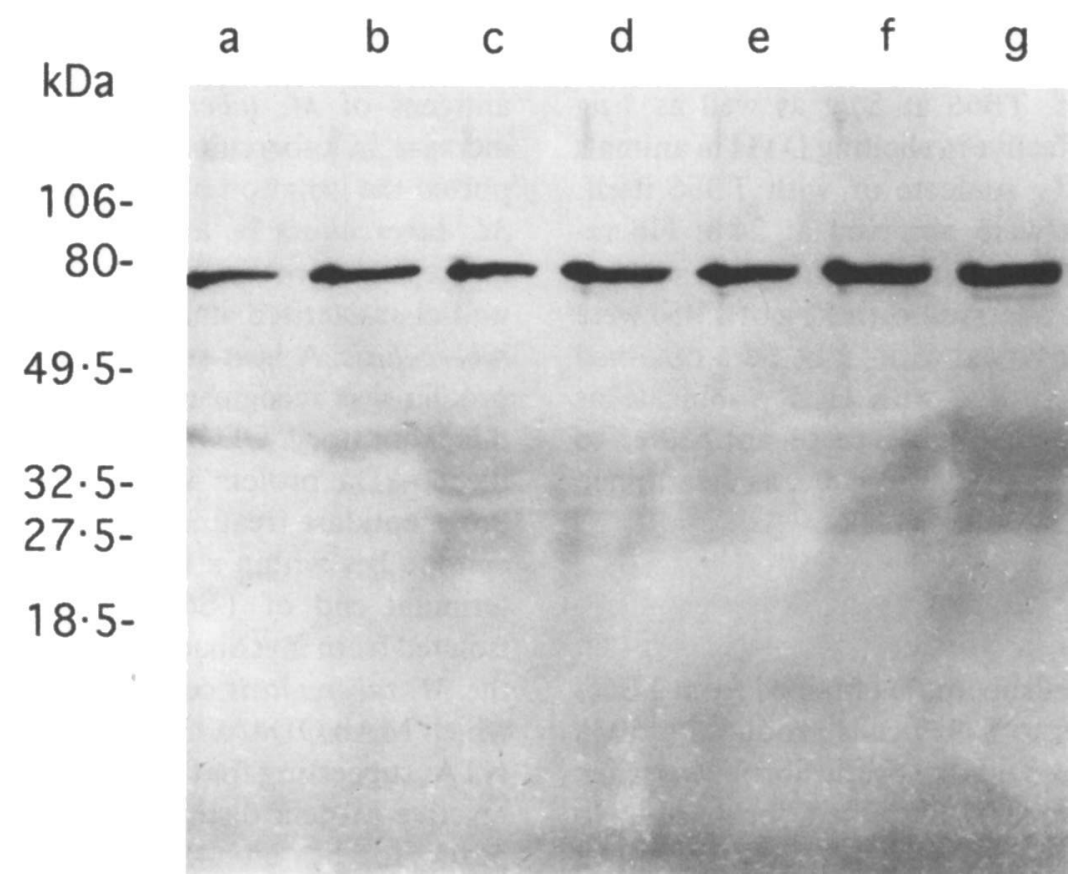

Fig. 2. Immunoblot analysis of IMAC fractions of: $\mathbf{a}, M$. bovis $\mathrm{BCG} ; \mathbf{b}, \mathrm{H}_{37} \mathrm{Ra} ; \mathbf{c}, M$. africanum; d, $M$. bovis; e, $\mathrm{H}_{37} \mathrm{Rv}$ and of $(\mathbf{f}) \mathrm{NaCl}$ and (g) EDTA eluates obtained by FN-Sepharose chromatography. MAb OD4AG3 was used as the primary antibody. The positions and mol. wts of the pre-stained markers are shown on the left.

$\left(\mathrm{OD}_{492}\right.$ c. $\left.0 \cdot 6\right)$. Also, TB66 bound to FN-coated wells could be detected with MAb OD4AG3 $\left(\mathrm{OD}_{492}\right.$ c. 0.7).

\section{Immunoreactivity of TB66}

TB66 obtained by IMAC of all the members of $M$. tuberculosis complex showed a very strong reaction with MAb OD4AG3 in immunoblotting (fig. 2a-e). TB66 obtained by FN-Sepharose chromatography of strain $\mathrm{H}_{37} \mathrm{Rv} \mathrm{CF}$ also showed the presence of OD4AG3 reactivity (fig. $2 \mathrm{f}$ and $\mathrm{g}$ ). No reaction was observed in the dot immunobinding assay with $\mathrm{MAb}$ OD4AG3 when TB66 was incubated with trypsin (fig. 3). Treatment of TB66 with a mixture of carboxypeptidases $\mathrm{A}$ and $\mathrm{B}$ for 15 min produced a protein of $c .60 \mathrm{kDa}$ which was not recognised by $\mathrm{MAb}$ OD4AG3 in the dot immunobinding assay (fig. 3).

\section{DTH reaction}

The results are summarised in the table as the average diameter of erythema observed in all animals 


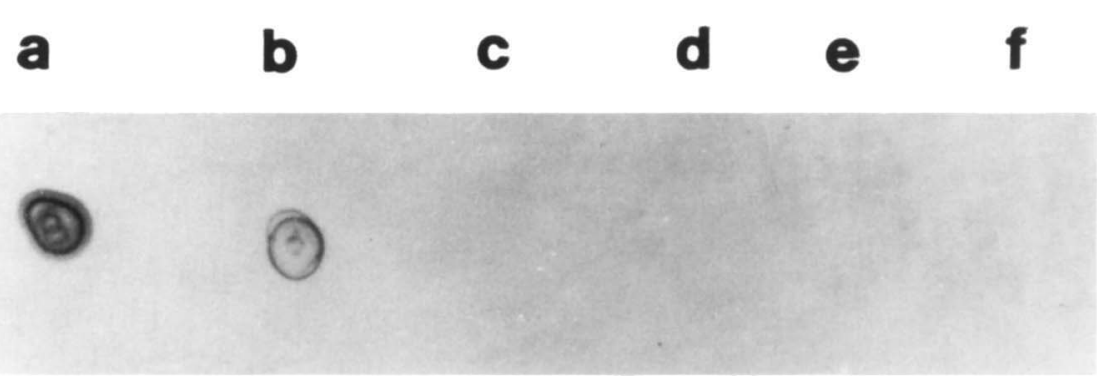

Fig. 3. Dot immunobinding assay of TB66 with MAb OD4AG3 : a, b, TB66 from H37Rv CS and CF; $\mathbf{c}, \mathbf{d}, \mathrm{TB} 66$ from CS and CF after trypsin treatment; e, f, TB66 from CS and CF after carboxypeptidase treatment.

Table. DTH reaction in guinea-pigs at $24 \mathrm{~h}$

\begin{tabular}{|c|c|c|c|c|}
\hline \multirow{3}{*}{$\begin{array}{l}\text { Average diameter (mm) } \\
\text { of erythema with } \\
\text { Sensitising antigen }\end{array}$} & \multicolumn{4}{|c|}{ Eliciting antigen } \\
\hline & \multicolumn{2}{|c|}{ TB66 } & \multirow{2}{*}{$\mathrm{H}_{37} \mathrm{Rv} \mathrm{CS}$} & \multirow{2}{*}{ PPD } \\
\hline & $1 \mu \mathrm{g}$ & $5 \mu \mathrm{g}$ & & \\
\hline $\mathrm{H}_{37} \mathrm{Rv}$ sonicate & 5 & 11 & 18 & 5 \\
\hline TB66 & 6 & 10 & 15 & 5 \\
\hline None (control) & NR & NR & NR & NR \\
\hline
\end{tabular}

NR, no reaction.

from a single group. TB66 at $5 \mu \mathrm{g}$ as well as $1 \mu \mathrm{g}$ concentration was effective in eliciting DTH in animals sensitised with $\mathrm{H}_{37} \mathrm{Rv}$ sonicate or with $\mathrm{TB} 66$ itself. Maximum reactions were observed at $24 \mathrm{~h}$. No reaction was observed in any animal from the control group. The reactions observed with $5 \mu \mathrm{g}$ of TB66 were greater than those observed with PPD. Sera obtained from guinea-pigs sensitised with $\mathrm{H}_{37} \mathrm{Rv}$ sonicate as well as TB66 showed the presence of antibodies to TB66. The titre in both cases was 4000 , as determined by ELISA.

\section{TNF assay}

Addition of $50 \mu$ l of supernate obtained from TB66treated macrophages to L-929 cells produced a $50 \%$ reduction in neutral red uptake by the fibroblasts when compared to the uptake by untreated fibroblasts. No cytotoxicity to the L-929 cells was observed when TB66 and supernate from untreated macrophages were added to the fibroblasts. Supernate from LPStreated macrophages produced a $75 \%$ reduction in the $\mathrm{A}_{570}$. A concentration as low as $1 \mu \mathrm{g}$ of TB66 stimulated TNF production by macrophages. TB66 preincubated with MAb OD4AG3 did not stimulate TNF production (no reduction in neutral red uptake), but protein incubated with MAb OD4AF1 caused a $45 \%$ reduction in the $A_{570}$.

\section{Discussion}

There is considerable interest in the identification of immunodominant and potentially protective protein antigens of $M$. tuberculosis because of the current increase in tuberculosis world wide. Earlier, we reported the isolation of a $66-\mathrm{kDa}$ protein (TB66) from $M$. tuberculosis in a single step by IMAC. ${ }^{11}$ This seroreactive protein was found to be distinct from the well-characterised immunodominant proteins of $M$. tuberculosis. A heat-stable and protein epitope of this protein was recognised by MAb OD4AG3 raised in this laboratory. OD4AG3-reactivity was abolished in the $60-\mathrm{kDa}$ protein which was produced after carboxypeptidase treatment of TB66, suggesting that the epitope lies within a 60 amino acid region at the Cterminal end of TB66. No such protein could be isolated from mycobacteria other than the members of the $M$. tuberculosis complex. Even MAC101, against which MAb OD4AG3 was raised, did not bind to NiNTA, suggesting that MAC101 possess an OD4AG3reactive protein distinct from TB66, which thus appears to be an $M$. tuberculosis-complex-specific protein.

TB66 was found to bind FN and could be purified by FN-Sepharose chromatography. Neither the salt nor the EDTA eluates obtained by FN-Sepharose chromatography contained the well-known FN-binding antigens of $M$. tuberculosis-i.e., the 30-32-kDa or the $57-60-\mathrm{kDa}$ proteins. ${ }^{6}$ It is possible that, under the conditions used here for chromatography, these proteins do not bind to $\mathrm{FN}$, or are bound to $\mathrm{FN}$ Sepharose but could not be eluted with $\mathrm{NaCl}$ or EDTA. Abou-Zeid et al. ${ }^{6}$ have reported their unsuccessful attempt to isolate the FN-binding antigens by FN-Sepharose, because of the strong binding of these antigens to FN. MAb OD4AG3 was found to bind strongly the synthetic 37 amino acid FN-binding 
peptide D3 (Sigma) $)^{17}$ in ELISA $\left(\mathrm{OD}_{492} c .0 \cdot 6\right)$. Binding of MAb OD4AG3 did not inhibit the FN-binding capacity of D3 or TB66, suggesting that the epitope recognised by this antibody is not involved in the FNbinding function. The OD4AG3-binding region of peptide D3 probably lies within the N1-N20 region of D3 because the FN-binding site has been shown to be within the 21-33 amino acid region. ${ }^{17}$

Mycobacterial preparations such as CF, PPD and antigen 5 are known to stimulate monocytes and alveolar macrophages to produce TNF. ${ }^{9} \mathrm{CF}$ proteins of $150,92,60,58,46$ and $20 \mathrm{kDa}$ have been reported to have TNF stimulating activity. ${ }^{10,18}$ This is the first report that a $66-\mathrm{kDa}$ protein of $M$. tuberculosis stimulates TNF production by macrophages in vitro. It remains to be determined whether, and how, TNF may be relevant to the immunopathogenesis of tuberculosis. The direct stimulatory effects of mycobacterial constituents may provide the basis for the apparent restricted specificity of suppression by monocytes in tuberculosis.

TB66 at a $1-\mu \mathrm{g}$ concentration produced DTH reactions in TB66- and $\mathrm{H}_{37} \mathrm{Rv}$-sensitised guinea-pigs.

\section{References}

1. Murray CJ, Styblo K, Rouillon A. Tuberculosis in developing countries: burden, intervention and cost. Bull Int Union Tuberc Lung Dis 1990; 65: 6-24.

2. Daniel TM, Debanne SM. The serodiagnosis of tuberculosis and other mycobacterial diseases by enzyme-linked immunosorbent assay. Am Rev Respir Dis 1987; 135: $1137-1151$

3. Daniel TM, Janicki BW. Mycobacterial antigens: a review of their isolation, chemistry, and immunological properties. Microbiol Rev 1978; 42: 84-113.

4. Stanford JL. Immunologically important constituents of mycobacteria: antigens. In: Ratledge C, Stanford J (eds) The biology of mycobacteria, vol. 2. Immunological and environmental aspects. London, Academic Press Inc. 1983: $85-127$.

5. Abou-Zeid C, Smith I, Grange JM, Ratliff TL, Steele J, Rook GAW. The secreted antigens of Mycobacterium tuberculosis and their relationship to those recognized by the available antibodies. J Gen Microbiol 1988; 134: 531--538.

6. Abou-Zeid C, Ratliff TL, Wiker HG, Harboe M, Bennedsen J, Rook GAW. Characterization of fibronectin-binding antigens released by Mycobacterium tuberculosis and $\mathrm{Myco}$ bacterium bovis BCG. Infect Immun 1988; 56: 3046-3051.

7. Hynes RO, Yamada KM. Fibronectins: muitifunctional modular glycoproteins. $J$ Cell Biol 1982; 95: 369-377.

8. Ratliff TL, McGarr JA, Abou-Zeid GAW et al. Attachment of mycobacteria to fibronectin-coated surfaces. J Gen Microbiol 1988; 134: 1307-1313.

9. Valone SE, Rich EA, Wallis RS, Ellner JJ. Expression of tumor necrosis factor in vitro by human mononuclear phagocytes
Also, $400 \mu \mathrm{g}$ of TB66/animal was sufficient to induce a good DTH reaction in guinea-pigs tested with TB66, $\mathrm{H}_{37} \mathrm{Rv}$ sonicate or PPD. A good antibody response to TB66 was elicited in all the guinea-pigs sensitised with TB66 or $\mathrm{H}_{37} \mathrm{Rv}$ sonicate. Antibodies to TB66 have been detected in sera from patients with tuberculosis, ${ }^{11}$ indicating the involvement of TB66 in the human antibody response to $M$. tuberculosis. The FN-binding property of TB66 could be important in the pathogenesis of $M$. tuberculosis. However, even avirulent members of the $M$. tuberculosis complex produce this protein, ruling out the possibility that TB66 is associated with virulence. The antigenicity of TB66 might be very beneficial in the development of a vaccine. It could also have potential as a reagent for DTH testing.

This work was supported by the US Leprosy Panel of the USJapan Co-operative Medical Service Program, administered by the National Institute of Allergy and Infectious Diseases (Grant I27189) and by the Association of Minority Health Professions Schools (AMHPS) AIDS Consortium. We are grateful to Drs T. Daniel, S. Chaparas, P. J. Brennan and J. Crawford for providing the mycobacterial strains and sonicates, and to Dr J.Pohl for sequencing the proteins. We thank Ms C. Willis for her technical assistance, Ms D. Floyd for her assistance in animal experiments, and Mr J. Perry for the illustrations. stimulated with whole Mycobacterium bovis BCG and mycobacterial antigens. Infect Immun 1988; 56:3313-3315.

10. Wallis RS, Amir-Tahmasseb M, Ellner JJ. Induction of interleukin 1 and tumor necrosis factor by mycobacterial proteins: the monocyte western blot. Proc Natl Acad Sci USA 1990; 87: 3348-3352.

11. Deshpande RG, Khan MB, Bhat DA, Navalkar RG. Purification and partial characterisation of novel $66-\mathrm{kDa}$ seroreactive protein of Mycobacterium tuberculosis $\mathrm{H}_{37}$ Rv. J Med Microbiol 1994; 41: 173-178.

12. Hochuli E, Dobeli E, Schacher A. New metal chelate adsorbent selective for proteins and peptides containing neighbouring histidine residues. J Chromatogr 1987; 411: 177-184.

13. Vuento M. Purification of fibronectin from human plasma by affinity chromatography under non-denaturing conditions. Biochem J 1979; 183: 331-337.

14. Towbin H, Staehelin T, Gordon J. Electrophoretic transfer of proteins from polyacrylamide gels to nitrocellulose sheets: procedure and some applications. Proc Natl Acad Sci USA 1979 ; 76: 4350-4354.

15. Deshpande RG, Khan MB, Navalkar RG. Immunoreactivity of a mammalian liver component with leprosy sera. Int Arch Allergy Immunol 1992; 97: 345-349.

16. Flick DA, Gifford GE. Comparison of in vitro cell cytotoxic assays for tumor necrosis factor. J Immunol Methods 1984; 68: $167-175$

17. McGavin MJ, Raucci G, Gurusiddappa S, Hook M. Fibronectin binding determinants of the Staphylococcus aureus fibronectin receptor. $J$ Biol Chem 1991; 266: 8343-8347.

18. Wallis RS, Paranjape R, Phillips M. Identification by twodimensional gel electrophoresis of a 58-kilodalton tumor necrosis factor-inducing protein of Mycobacterium tuberculosis. Infect Immun 1993; 61 : 627-632. 